\title{
EFFECT OF PENETRATION ENHANCERS ON IN VITRO PERMEATION OF NYSTATIN FROM TOPICAL FORMULATIONS
}

\author{
MARZOUK M.A. ${ }^{*}$, AMMAR A.A., DARWISH M.K. AND EL-SAYED H.A. \\ Pharmaceutics Department, Faculty of Pharmacy (Girls), Al-Azhar University, Cairo, Egypt. \\ *Corresponding Author: Email- maboushady2000@yahoo.com
}

Received: July 10, 2012; Accepted: July 26, 2012

\begin{abstract}
Nystatin is a polyene antifungal drug that is of particular interest because it exhibits remarkable action against a wide range of pathogenic and non-pathogenic yeast and fungi. Transdermal and topical delivery of drugs provide advantages over conventional oral administration. The benefit of transdermal systems includes convenience, improved patient compliance and elimination of hepatic first pass effect. The aim of this work is to formulate and evaluate topical gel containing nystatin and to improve the antifungal activity of nystatin through using different penetration enhancers namely propylene glycol (PG) 10\%, polyethyleneglycol (PEG) 400, ethanol, oleic acid, eucalyptus oil, tween 80 each in concentration of $5 \%$ and dimethylformamide (DMF) $3 \%$ with objectives of prolonging its action. The formulae showing the best drug release were selected to study the effect of storage on drug content and pH measurements over a period of 3 months and finally for microbiological evaluation. Among different penetration enhancers used, propylene glycol showed the highest effect on the amount drug permeated followed by dimethylformamide.
\end{abstract}

Keywords- Nystatin, Enhancers, Gel- dimethylformamide, propylene glycol, polyethyleneglycol

Citation: Marzouk M.A., et al (2012) Effect of Penetration Enhancers on In Vitro Permeation of Nystatin From Topical Formulations. International Journal of Drug Discovery, ISSN: 0975-4423 \& E-ISSN: 0975-914X, Volume 4, Issue 2, pp.-153-159.

Copyright: Copyright@2012 Marzouk M.A., et al This is an open-access article distributed under the terms of the Creative Commons Attribution License, which permits unrestricted use, distribution and reproduction in any medium, provided the original author and source are credited.

\section{Introduction}

In vitro percutaneous absorption experiments are usually conducted in a model system using a diffusion cell, in which an artificial membrane representative of the epidermal barrier is fixed. Animal or human skin may also be used instead of the artificial membrane, such a system does not simulate the in vivo condition in which an efficient and variable blood supply removes the penetrating drug at various rates.

Although in vitro methods are of limited values, yet they are important means of assessing the ability of a vehicle to release the drug, to determine the general routes of penetration and to compare the efficacy of various solvents, or other adjuvants on percutaneous absorption from a new dosage form.

Penetration enhancers are taken as additives incorporated into a formulations in order to promote the absorption of drugs from ointments or gels. In an attempt to enhance the drug release from the prepared gels, a representative model from previous study containing carpobol 934 (Cp934 1\%), sodium carboxymethyl cellulose (NaCMC 5\%), methyl cellulose (MC3\%), hydroxypropylmethylcellulose (HPMC3\%) and Poloxamer 407 (Polox407 20\%) were chosen to modulate nystatin release by the use of various penetration enhancers namely propylene glycol, dimethylformamide, polyethylene glycol 400, ethanol, eucaluptus oil, oleic acid and tween 80 . These enhancers are commonly used as effective penetration enhancers for many drugs $[1,4,6,14,15]$.

In this study, permeation rates of nystatin from different bases through cellulose membrane and rabbit skin were studied. In addition, the effect of penetration enhancers on permeation rates of nystatin from selected formula was investigated.

\section{Materials}

Nystatin pure sample and Carbopol 934 and triethanolamine were kindly supplied by Delta pharma (Egypt). Disodium hydrogen phosphate, potassium dihydrogen phosphate, methyl cellulose and Carboxymethylcellulose sodium powders from El- Nasr Pharmaceutical Co. (Egypt). Hydroxypropylmethylcellulose powder low viscosity (6000) from Sigma Chemical Co. (USP). Poloxamer 407 was kindly supplied by the Egyptian International Pharmaceutical Industries Co (EPICO), Egypt. Dimethylformamide (DMF) and propylene glycol (PG) (Misr Chemical co., Cairo, Egypt). Pure pharmaceutical grades of: Polyethylene glycol 400 (PEG), ethanol, eucalyptus oil, oleic acid and tween 80. Cellulose membrane, molecular weight cut-off 10,000 (Arthur H. Thomas Co., Philadeliphia, Pa, USA). Sabouraud's agar, consisting of $2 \%$ glucose, $1 \%$ neopeptone and 2\% agar, Oxoid Co., (England). Strain of fungi such as Candida albicans ATCC (American typing culture collection). 


\section{Methods}

\section{Preparation of Gel Bases Containing Penetration Enhancers}

Five gel bases from previous work [11] were selected that have highest release and they are: F1 (Cp934 1\%), F2 (NaCMC 5\%), F3 (MC3\%), F4 (HPMC3\%) and F5 (Polox407 20\%).To study the effect of penetration enhancers on the in vitro permeation (namely, PG 10\%, PEG 400, ethanol, oleic acid, eucalyptus oil, tween 80 each in concentration of $5 \%$ and DMF $3 \%$ ) were used to produce 35 formulations as shown in table 1. Each of the previous penetration enhancers, at the corresponding concentration, was added from the beginning during the preparation of the gel bases.

\section{Effect of Enhancers on the In Vitro Permeation of Nystatin,} From Different Bases, through Cellulose Membrane

The outer tube of a plastic syringe, $10 \mathrm{ml}$ capacity (Henka-Sass, Wolf $\mathrm{GmbH}$ Tuttingen, Germany), was cut smoothly to whole diameter near the nozzle and was used as donor compartment. Accurately weighed $0.082 \mathrm{gm}$ of each of the different bases containing $1.72 \%$ nystatin was introduced into the tube at the cut end and levelled with a stainless steel weighing spatula. Cellulose membrane, previously soaked for 24 hours in the buffer solution of $\mathrm{pH}$ 6.4 , was then stretched around the cut end touching the base, with effective permeation area of $3.14 \mathrm{~cm}^{2}$. The membrane was fixed around the tube with rubber band and its edges were sealed with an adhesive tape. The whole tube was hanged into a $100 \mathrm{ml}$ glass beaker (as receptor compartment) containing $50 \mathrm{ml}$ of buffer solution of $\mathrm{pH} 6.4$ at $37^{\circ} \mathrm{C}$, so that the cut end of the tube, covered with cellulose membrane, is in the center of the liquid. The buffer solution in the receptor compartment was stirred at 150 r.p.m. throughout the time of the diffusion studies. At specified time intervals for $24 \mathrm{hr}, 0.7 \mathrm{ml}$ samples were withdrawn from the receptor compartment. The drug was determined spectrophotometrically at $\lambda_{\max } 306$ $\mathrm{nm}$ using Jenway spectrophotometer (Model 6105UV/Nis, England). A control sample is obtained from diffusion cell under the same experimental conditions, using the medicated base without enhancer. Each sample withdrawn was replaced by an equal volume of the buffer solution [11]. Sink condition was maintained throughout the experiment.

\section{Effect of Enhancers on the In Vitro Permeation of Nystatin, from Different Gel Bases, through Rabbit Skin}

\section{Preparation of a Rabbit Skin}

Dorsal full-thickness skin of male rabbit was obtained from white Newzealand rabbits weighing $3-4 \mathrm{~kg}$. The skin was carefully removed from animals and after sacrificing them, the hair was clipped without damaging the skin. The fat was removed with the aid of scissor and skin was washed and the excised full thickness rabbit skin samples were stored at $20^{\circ} \mathrm{C}$ prior to use $[8,19]$. The excised full thickness rabbit skin samples were equilibrated by soaking in buffer solution of $\mathrm{pH} 6.4$ for about one hour before beginning of each experiment [9].

\section{In Vitro Permeation Studies}

The first ten formulations that gave best $Q$ (the cumulative amount of drug penetrates through the unit surface area of the membrane) after 24 hours were chosen for in vitro permeation studies of nystatin through dorsal rabbit skin.
The same procedure for testing permeation through cellulose membrane was applied with the exception that the prepared skin samples were mounted on the donor compartment of the assembled permeation cell with the stratum corneum facing upward and the dermal side facing downward with permeation area of $3.14 \mathrm{~cm}^{2}$. The donor compartment was kept hanged on the receptor compartment and secured tightly with the help of clamps. The receptor compartment was then filled with $50 \mathrm{ml}$ of phosphate buffer solution of $\mathrm{pH}$ 6.4. The temperature of media was maintained at $37 \pm 0.5^{\circ} \mathrm{C}$. The amount of drug permeated through rabbit skin per unit area $\left(\mu \mathrm{g} / \mathrm{cm}^{2}\right)$ was plotted against time (hours) [16].

\section{Calculation of Permeation Parameters Across Cellulose Mem- brane and Rabbit Skin}

Different permeation parameters of nystatin was calculated such as steady state fluxes $\left(\mathrm{J}_{\mathrm{ss}}\right)$ that were calculated from the slope of the portion of the amount permeated through unit area of the cellulose membrane or rabbit skin versus time plot [5]. Permeability coefficient $\left(K_{p}\right)$ through cellulose membrane or rabbit skin, Diffusion coefficient (D) within the cellulose membrane or rabbit skin and lag time ( $\left.t_{L}\right)$ were calculated from the penetration data.

\section{Accelerated Stability Testing of Different Gel Bases}

Six gel formulations that gave highest drug amount permeated from rabbit skin were chosen to study their stability are: F1E3 (Cp934 1\% gel containing 10\% propylene glycol). F1E5(Cp934 1\% gel containing 3\% dimethyl formamide). F4E3 (HPMC $3 \%$ containing $10 \%$ propylene glycol). F4E5 (HPMC $3 \%$ containing 3\% dimethyl formamide). F5E3 (Polox407 20\% gel containing 10\% propylene glycol). F5E5 (Polox407 20\% gel containing 3\% dimethyl formamide).

Enough amount of each base was stored at temperatures of $4{ }^{\circ} \mathrm{C}$, $25^{\circ} \mathrm{C}$ and $37^{\circ} \mathrm{C}$ in refrigerator and thermostatically controlled hot air ovens respectively. Adequate samples of these bases, at each temperature, were obtained at the beginning of the experiment and at time intervals of $7,14,30,45,60,75$ and 90 days. The obtained samples were subjected to the drug content assay and $\mathrm{pH}$ measurement.

\section{Microbiological study}

The agar medium was prepared by dissolving $65 \mathrm{gm}$ of sabouraud dextrose agar powder per liter of distilled water and was sterilized using autoclave at $121{ }^{\circ} \mathrm{C}$ for $20 \mathrm{~min}$. The indicator isolate of Candida albicans was inoculated into sabouraud's dextrose agar plate and was incubated for $48 \mathrm{hr}$ prior to testing. Once actively growing colonies of Candida albicans is obtained, a single well isolated colony was picked with a wire loop from sabouraud's dextrose agar plate and inoculated in sterilized normal saline and its turbidity is adjusted to match that of standard of $0.5 \mathrm{M}$ McFarland barium sulfate, that is to contain approximately $10^{7} \mathrm{cells} / \mathrm{ml}$. The isolate of Candida albicans was seeded from standardized suspension to a concentration of $3 \mu \mathrm{l}$ per $\mathrm{ml}$ in agar medium, the seeded agar medium was poured into Petri-dishes $(15 \mathrm{~cm}$ diameter) to a depth of about $4 \mathrm{~mm}$ and numbers of wells in each dish were cut using Wassermann tube of $6 \mathrm{~mm}$ diameter $[2,17]$.

The antifungal efficacy of nystatin gels and commercial nystatin cream was determined by performing agar-cup diffusion assay. 
The effectiveness of the prepared nystatin gel against Candida albicans was studied, by applying $0.4 \mathrm{gm}$ of the gel and an equivalent weight of commercial cream on the sabouraud dextrose agar which was previously seeded with Candida albicans. The Petri dishes were then incubated at $25^{\circ} \mathrm{C}$. The effectiveness of the prepared gel was compared with plain gel contains $0 \%$ of nystatin and the commercial nystatin cream contains 100,000 I.U. of nystatin / $1 \mathrm{gm}$ (Nystatin $\AA$, PHARAONIA). The zones of growth inhibition were measured for all the tested samples. Each type of the samples was tested in triplicate (Mohamed, 2004, 1]. The inhibition zone of growth of Candida albicans was measured in $\mathrm{mm}$ after 24 and $48 \mathrm{hrs}$ and the mean inhibition zone was then calculated.

\section{Results and Discussion}

Effect of enhancers on the in vitro permeation of nystatin, from different formulations through cellulose membrane

Results of nystatin permeated $\left(\mathrm{Q} / \mathrm{A}, \mu \mathrm{g} / \mathrm{cm}^{2}\right)$ from different gel bases through cellulose membrane and commercial cream are shown in Fig. 1-6.

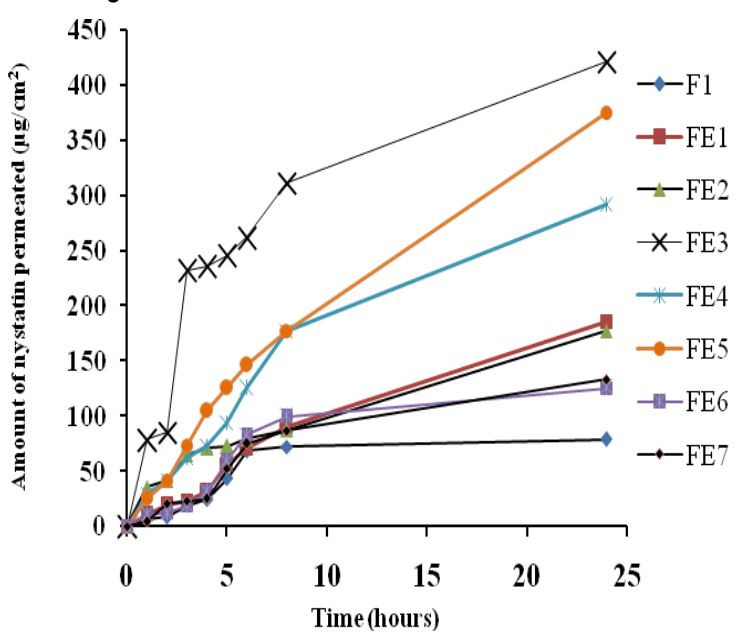

Fig. 1- In vitro permeation profiles of nystatin, from carbopol $1 \%$ gel base in presence of penetration enhancers through cellulose membrane into buffer solution of $\mathrm{pH} 6.4$

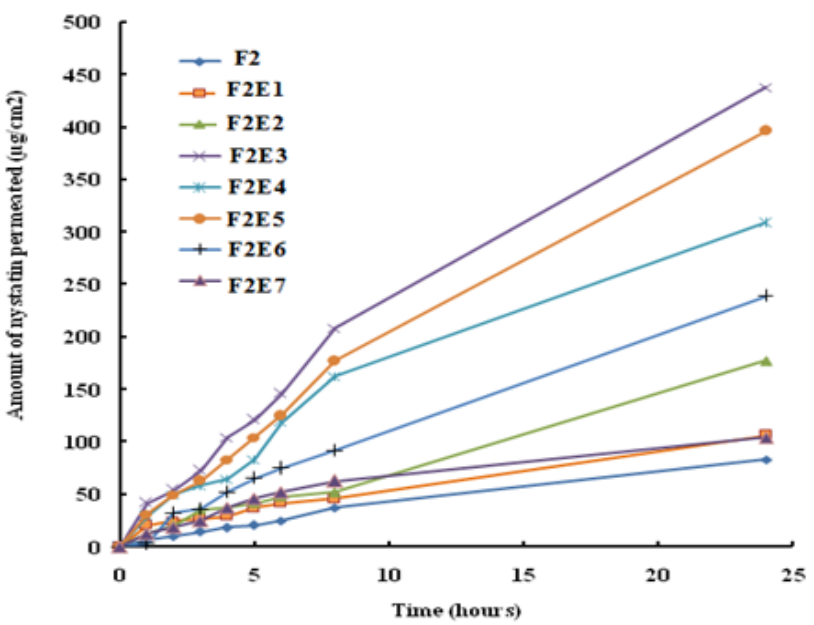

Fig. 2- In vitro permeation profiles of nystatin, from $\mathrm{NaCMC} \%$ gel base in presence of penetration enhancers through cellulose membrane into buffer solution of $\mathrm{pH} 6.4$

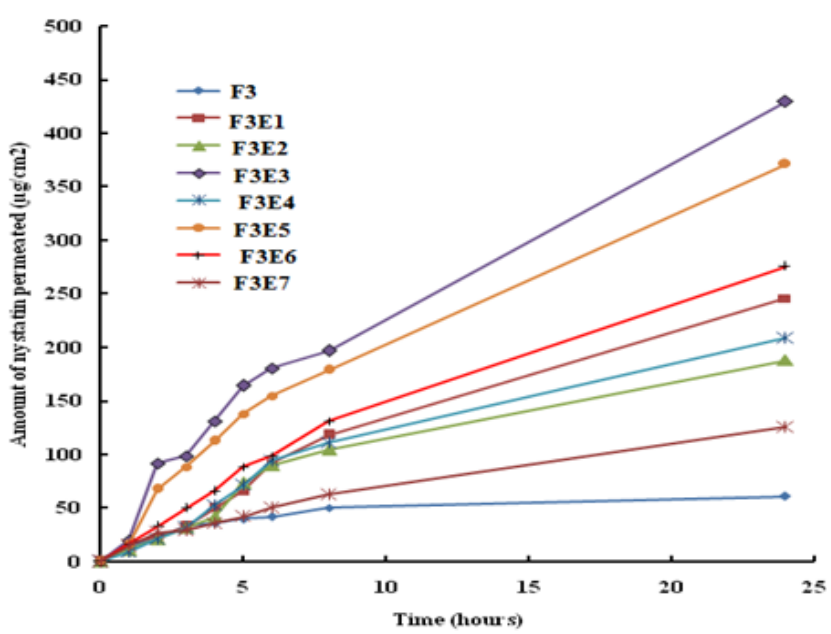

Fig. 3- In vitro permeation profiles of nystatin, from $\mathrm{MC} \%$ gel base in presence of penetration enhancers through cellulose membrane into buffer solution of $\mathrm{pH} 6.4$

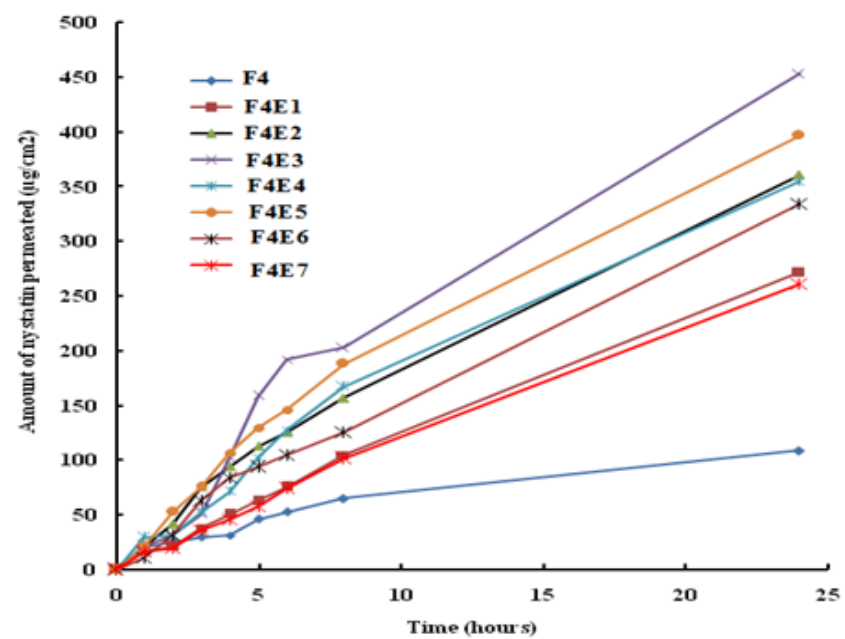

Fig. 4- In vitro permeation profiles of nystatin, from HPMC $3 \%$ gel base in presence of penetration enhancers through cellulose membrane into buffer solution of $\mathrm{pH} 6.4$

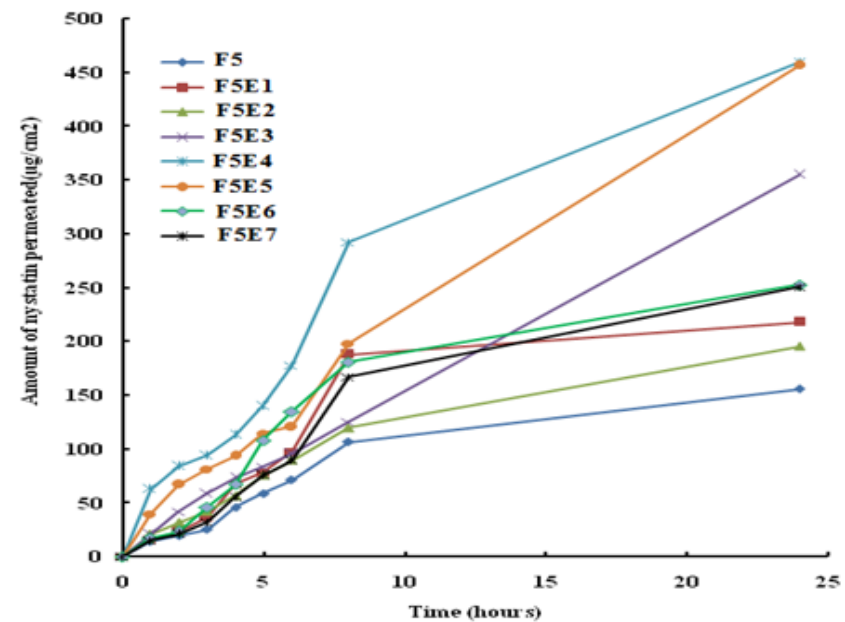

Fig. 5- In vitro permeation profiles of nystatin from $20 \%$ Poloxamer gel base in presence of penetration enhancers through cellulose membrane into buffer solution of $\mathrm{pH} 6.4$ 


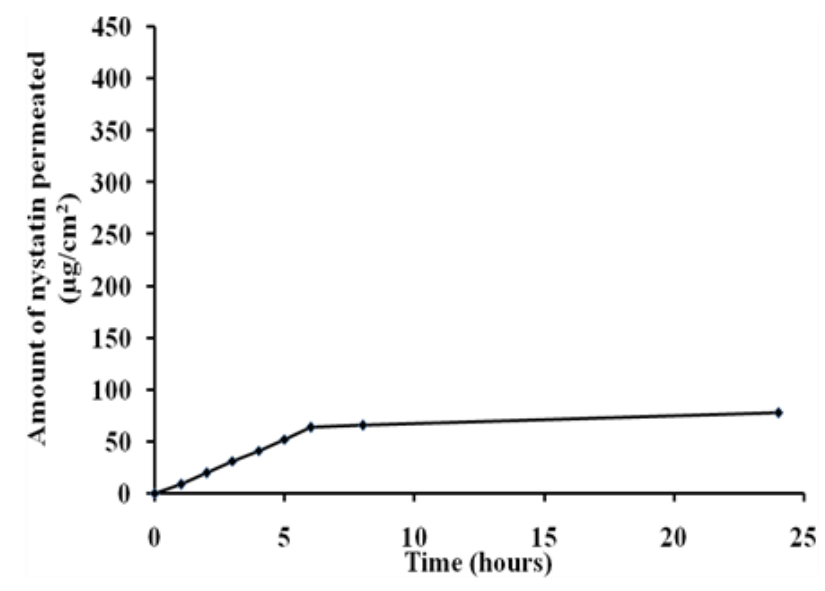

Fig. 6- Nystatin permeation from commercial nystatin cream into buffer solution of $\mathrm{pH} 6.4$ through cellulose membrane

It was concluded that formula with PG was followed by formula containing DMF in their high rate of drug permeation.

The effect of propylene glycol, DMF, as chemical enhancers, on the permeation of nystatin through cellulose membrane may be due to the high solvent power of each on the drug. PG may function simply as co-solvent to produce saturated or nearly saturated solution of the active ingredient and thereby it maximizes the thermodynamic activity of the penetrant [10]. Also, PG increases drug partitioning and drug permeation [20]. A further advantage of these polyhydroxy compounds that they act as humectants, to prevent drying and crusting of the vehicles [4,12].

Effect of enhancers on the in vitro permeation of nystatin, from different formulations through rabbit skin

Permeation results of nystatin from different gel bases, in presence of enhancers and commercial nystatin cream using dorsal rabbit skin, are shown in Fig. 7 and 8.

It was found that the permeation of nystatin through dorsal rabbit skin from all gel bases was significantly higher than that obtained from the commercial nystatin cream and followed a membrane controlled system.

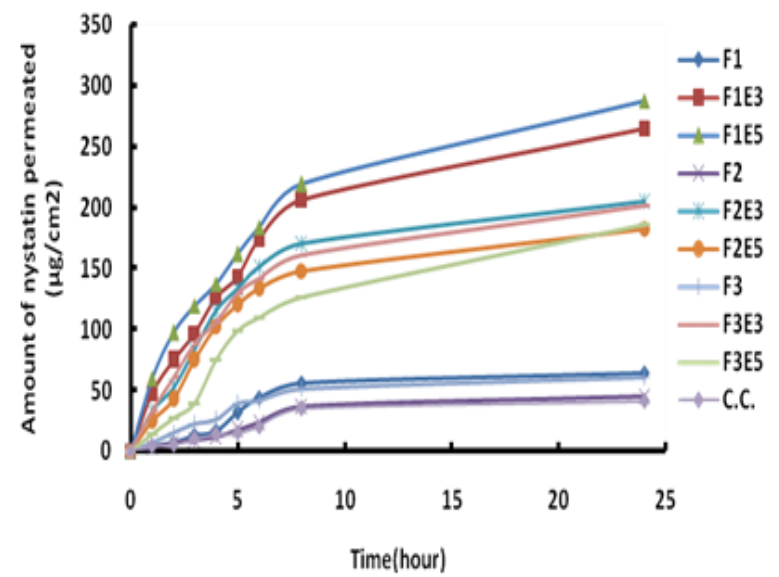

Fig. 7- In vitro permeation profiles of nystatin from different gel base in presence of penetration enhancers into buffer solution of pH 6.4, using rabbit skin. N.B.: C.C. is commercial cream

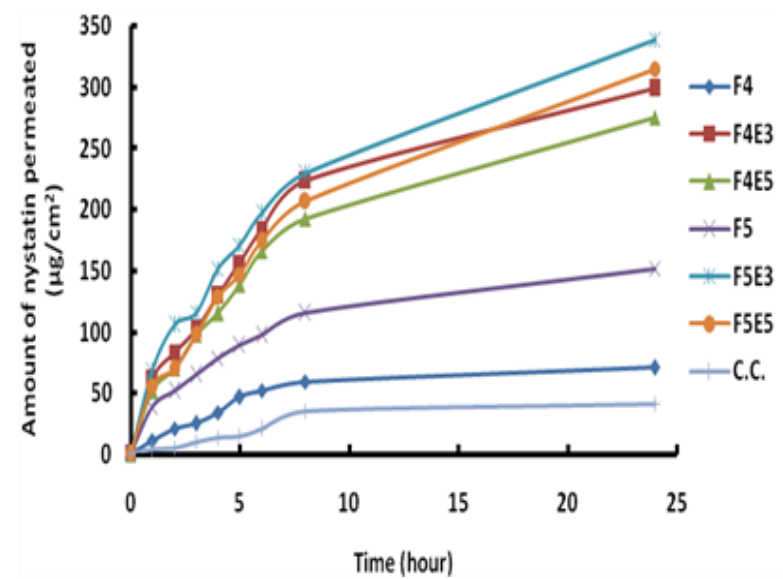

Fig. 8- In vitro permeation profiles of nystatin from different gel base in presence of penetration enhancers into buffer solution of

pH 6.4, using rabbit skin. N.B.: C.C. is commercial cream

Calculation of Permeation Parameters for Nystatin formulations using Cellulose membrane and rabbit skin

The permeation data were treated according to zero order or membrane diffusion controlled model and the permeation parameters calculated according to Fick's law, like flux (Jss), Diffusion Coefficient (D), Permation Coefficient $(P)$ and Lag time ( $\left.t_{L}\right)$ were obtained. Also the enhancement ratio was calculated according to the following formula:

\section{E.R. $=\frac{K p \text { in Presence of Enhancer }}{K p \text { in Absence of Enhancer }}$}

Permeation parameters obtained, according to Fick's law are shown in tables 2 and 3 . The flux coefficient values increased, suggesting that permeation of nystatin increased with the addition of enhancers. Addition of PG increased the steady state flux value. This suggests that the permeation of nystatin increased with the addition of propylene glycol. The solubility of the drug in the vehicle is influenced by the partition coefficient of the drug. Addition of $P G$ might have increased the solubility of the drug and hence partition coefficient of the drug between the gel and barrier, which in turn increased the penetration rate of drug. This is in agreement with [13].

Table 2- Permeation parameters of nystatin from gel bases, in presence of penetration enhancers through cellulose membrane.

\begin{tabular}{|c|c|c|c|c|c|}
\hline Formulations & $\begin{array}{l}\text { Steady-state } \\
\text { s flux (Jss) } \\
\left(\mu \mathrm{g} \cdot \mathrm{cm}^{-2} \cdot \mathrm{hr}^{-1}\right)\end{array}$ & $\begin{array}{l}\text { Lag time } \\
\text { (t.)(hr) }\end{array}$ & $\begin{array}{l}\text { Diffusion } \\
\text { coefficient } \\
\text { (D) }\left(\mathrm{cm}^{2} . \mathrm{hr}^{-1}\right)\end{array}$ & $\begin{array}{l}\text { Permeability } \\
\text { coefficient } \\
\left(K_{p}\right)\end{array}$ & $\begin{array}{l}\text { Enhancement } \\
\text { ratio (ER) }\end{array}$ \\
\hline F1 & 0.35 & 48.25 & 2.73 & 0.25 & ----- \\
\hline F1E1 & 2.06 & 4.81 & 2.74 & 1.45 & 6.02 \\
\hline F1E2 & 1.75 & 8.22 & 1.6 & 1.23 & 5.11 \\
\hline F1E3 & 2.75 & 25.04 & 5.27 & 1.93 & 8.04 \\
\hline F1E4 & 2.99 & 7.55 & 1.74 & 2.1 & 8.74 \\
\hline F1E5 & 4.09 & 5.27 & 2.5 & 2.87 & 11.94 \\
\hline F1E6 & 0.85 & 23.52 & 5.61 & 0.6 & 2.49 \\
\hline F1E7 & 1.15 & 13.27 & 9.9 & 0.81 & 3.37 \\
\hline F2 & 1.02 & 2.33 & 5.67 & 0.71 & ----- \\
\hline $\mathrm{F} 2 \mathrm{E} 1$ & 1.16 & 5.14 & 2.57 & 0.81 & 1.14 \\
\hline F2E2 & 2.32 & 0.2 & 6.47 & 1.62 & 2.29 \\
\hline F2E3 & 4.4 & 5.05 & 2.61 & 3.08 & 4.33 \\
\hline F2E4 & 3.47 & 4.72 & 2.79 & 2.42 & 3.41 \\
\hline F2E5 & 4.21 & 3.86 & 3.42 & 2.94 & 4.15 \\
\hline
\end{tabular}


Table 2- Continue

\begin{tabular}{|c|c|c|c|c|c|}
\hline Formulations & $\begin{array}{l}\text { Steady-state } \\
\text { flux (Jss) } \\
\left(\mu g . \mathrm{cm}^{-2} \mathrm{hr}^{-1}\right)\end{array}$ & $\begin{array}{l}\text { Lag time } \\
\left(\mathrm{t}_{\mathrm{L}}\right)(\mathrm{hr})\end{array}$ & $\begin{array}{l}\text { Diffusion } \\
\text { coefficient } \\
\text { (D) }\left(\mathrm{cm}^{2} \cdot \mathrm{hr}^{-1}\right)\end{array}$ & $\begin{array}{l}\text { Permeability } \\
\text { coefficient } \\
\left(K_{p}\right)\end{array}$ & $\begin{array}{l}\text { Enhancement } \\
\text { ratio (ER) }\end{array}$ \\
\hline F2E6 & 2.91 & 2.17 & 6.08 & 2.03 & 2.86 \\
\hline F2E7 & 0.93 & 11.87 & 1.11 & 0.65 & 0.92 \\
\hline F3 & 0.32 & 37.58 & 3.51 & 0.22 & ----- \\
\hline F3E1 & 2.83 & 3.93 & 3.36 & 1.98 & 8.98 \\
\hline F3E2 & 1.81 & 9.34 & 1.41 & 1.26 & 5.74 \\
\hline F3E3 & 3.7 & 9.35 & 1.41 & 2.59 & 11.76 \\
\hline F3E4 & 2.14 & 7.21 & 1.83 & 1.5 & 6.81 \\
\hline F3E5 & 3.6 & 7.54 & 1.75 & 2.51 & 11.43 \\
\hline F3E6 & 3.08 & 4.56 & 2.89 & 2.16 & 9.8 \\
\hline F3E7 & 1.35 & 5.79 & 2.28 & 0.94 & 4.28 \\
\hline $\mathrm{F} 4$ & 0.99 & 10.39 & 1.21 & 0.7 & ----- \\
\hline F4E1 & 3.46 & 1.09 & 1.21 & 2.42 & 3.5 \\
\hline F4E2 & 3.96 & 4.22 & 3.13 & 2.77 & 4.02 \\
\hline F4E3 & 3.93 & 8.61 & 1.53 & 2.75 & 3.98 \\
\hline F4E4 & 4.07 & 3.96 & 3.34 & 2.85 & 4.12 \\
\hline F4E5 & 4.04 & 5.84 & 2.26 & 2.82 & 4.09 \\
\hline F4E6 & 4.06 & 2.16 & 6.1 & 2.84 & 4.11 \\
\hline F4E7 & 3.32 & 1.07 & 1.23 & 2.32 & 3.37 \\
\hline F5 & 1.46 & 10.53 & 1.25 & 1.02 & ----- \\
\hline F5E1 & 1.94 & 13.08 & 1.01 & 1.36 & 1.33 \\
\hline F5E2 & 1.87 & 9.64 & 1.37 & 1.31 & 1.28 \\
\hline F5E3 & 4.11 & 9.16 & 1.44 & 2.87 & 2.81 \\
\hline F5E4 & 4.56 & 0.76 & 1.74 & 3.19 & 3.13 \\
\hline F5E5 & 4.82 & 3.12 & 4.23 & 3.37 & 3.31 \\
\hline F5E6 & 2.12 & 14.65 & 9.01 & 1.48 & 1.45 \\
\hline F5E7 & 2.67 & 6.6 & 2 & 1.87 & 1.83 \\
\hline $\begin{array}{l}\text { Commercial } \\
\text { cream }\end{array}$ & 1.22 & 8.988 & 1.46 & 0.85 & ----- \\
\hline
\end{tabular}

Table 3 - Permeation parameters of nystatin from gel bases, in presence of enhancers and commercial cream through rabbit skin through rabbit skin.

\begin{tabular}{|c|c|c|c|c|c|}
\hline Formulations & $\begin{array}{l}\text { Steady-state } \\
\text { flux Jss } \\
\left(\mu \mathrm{g} \cdot \mathrm{cm}^{-2} \mathrm{hr}^{-1}\right)\end{array}$ & $\begin{array}{l}\text { Lag time } \\
\text { (tL) (hr) }\end{array}$ & $\begin{array}{l}\text { Diffusion } \\
\text { coefficient } \\
\text { (D) }\left(\mathrm{cm}^{2} . \mathrm{hr}^{-1}\right)\end{array}$ & $\begin{array}{l}\text { Permeabilit } \\
\text { y coefficient }\end{array}$ & $\begin{array}{l}\text { Enhancement } \\
\text { t ratio(ER) }\end{array}$ \\
\hline F1 & 0.56 & 42.19 & 3.21 & 0.39 & -ב-ב- \\
\hline F1E3 & 1.88 & 25.63 & 5.2 & 1.314 & 3.37 \\
\hline F1E5 & 1.73 & 25.38 & 5.15 & 1.207 & 3.1 \\
\hline F2 & 0.51 & 41.18 & 3.45 & 0.353 & ---- \\
\hline F2E3 & 1.02 & 39.26 & 3.2 & 0.71 & 2.01 \\
\hline F2E5 & 0.93 & 26.35 & 3.36 & 0.65 & 1.84 \\
\hline F3 & 0.49 & 36.51 & 3.61 & 0.346 & -.-- \\
\hline F3E3 & 1.08 & 35.97 & 3.66 & 0.757 & 2.19 \\
\hline F3E5 & 1.37 & 38.22 & 6.76 & 0.958 & 1.27 \\
\hline F4 & 0.71 & 26.35 & 5.01 & 0.498 & -.-- \\
\hline F4E3 & 2.09 & 22.01 & 5.99 & 1.465 & 2.94 \\
\hline F4E5 & 2.04 & 19.36 & 6.81 & 1.428 & 2.87 \\
\hline F5 & 0.96 & 26.78 & 4.93 & 0.671 & ---- \\
\hline F5E3 & 2.59 & 17.99 & 7.33 & 1.811 & 2.7 \\
\hline F5E5 & 2.59 & 15.19 & 8.69 & 1.808 & 2.69 \\
\hline nystatin cream & 0.57 & 52 & 4.53 & 0.398 & -.-- \\
\hline
\end{tabular}

\section{Accelerated stability testing of different gel bases}

A little change in the $\mathrm{pH}$ values after storage was observed. The $\mathrm{pH}$ range for all formulations was found to be (4.63-6.13). The $\mathrm{pH}$ range for formulations stored at 4,25 and $37{ }^{\circ} \mathrm{C}$ was (4.7-6.13), (4.65-5.79) and (4.63-5.16) respectively.

Histogram showing percent nystatin retained in gel formu-lations after 90 days at different temperatures (Fig. 9.)

Table 4 shows the average $t_{1 / 2}$ and tgo values for nystatin gel formu- ations based on accelerated stability testing at $20^{\circ} \mathrm{C}$.

Generally, the long t9o indicated high stability of nystatin in the investigated gels. The high stability may be explained by the absence of interaction or complexation between drug and the other excipient present in the same formula. However, the shortest t90 indicated higher rate of decomposition.

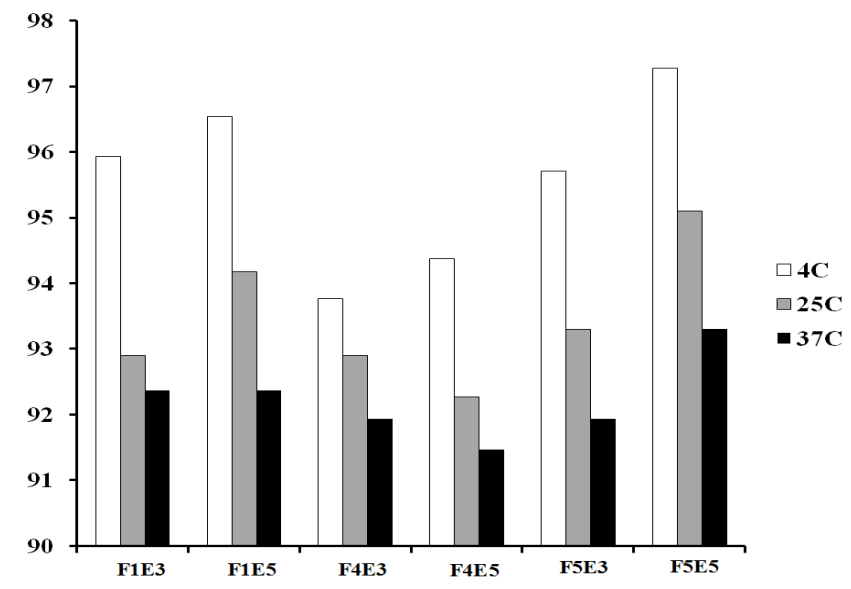

Fig. 9- Histogram showing percent nystatin retained in gel formulations after 90 days.

Table 4 - t1/2 and t90 values for nystatin gel formuations based on accelerated stability testing at $20^{\circ} \mathrm{C}$.

\begin{tabular}{|lll|} 
Formulations & Average $\mathrm{t}_{1 / 2}$ at $20^{\circ} \mathrm{C}$ (year) & Average too at $20^{\circ} \mathrm{C}$ (year) \\
\hline F1E3 & 2.4396 & 0.4879 \\
F1E5 & 1.685 & 0.337 \\
F4E3 & 2.0112 & 0.4022 \\
F4E5 & 2.5095 & 0.5019 \\
F5E3 & 2.3307 & 0.4661 \\
F5E5 & 3.1948 & 0.639 \\
\hline
\end{tabular}

\section{Microbiological study}

Fig. 10 shows a histogram of the mean values of inhibition zones of nystatin gel bases and its commercial cream at 24 and $48 \mathrm{hrs}$. Fig. 11 shows the photograph of inhibition zones of different nystatin gel formulations after 24 and 48 hrs. It was found that the antifungal activity of all nystatin gels was found to be greater than this of commercial nystatin cream, this is in agreement with [1].

The experimental data were statistically analyzed using one-way analysis of variance (ANOVA) followed by Tukey Kramer (post tests) for multiple comparison. It was observed that the values of inhibition zones of all nystatin gels are non significant with each other at $p>0.05$, except all gel bases vs. plain gels and commercial cream showing significance at $p<0.001$. It was noted that the antifungal activity of nystatin gel as well as commercial cream after $48 \mathrm{hr}$ is lower than that after $24 \mathrm{hr}$. There was a statistically significant difference ( $p$ value of 0.0163 ) in the inhibitory zones at $24 \mathrm{hrs}$ and $48 \mathrm{hrs}$ with maximum inhibition at $24 \mathrm{hr}$, irrespective of the concentration. This can be explained by the fact that, Candida albicans will be in log phase during 24 hrs and reaches stationary phase at $48 \mathrm{hrs}$. This was in agreement with [18]. Using Pearson correlation, it was found that the amounts of nystatin permeated through rabbit skin can be highly correlated with the values of inhibition zones $(r=0.912)$ at $p$ value less than 0.05 . 


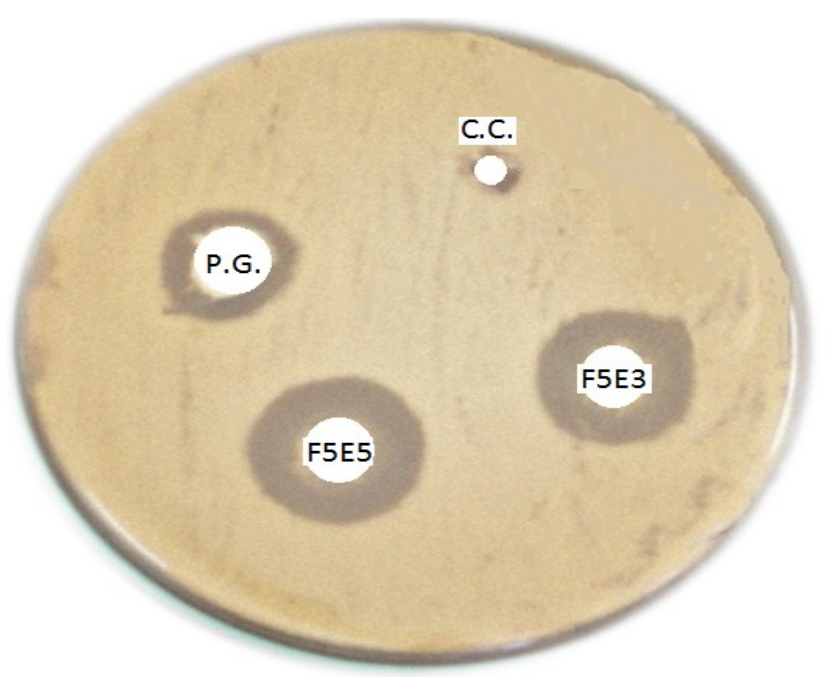

Fig. 10- Histogram showing the mean values of inhibition zones of nystatin gel bases and its commercial cream at 24 and $48 \mathrm{hrs}$.

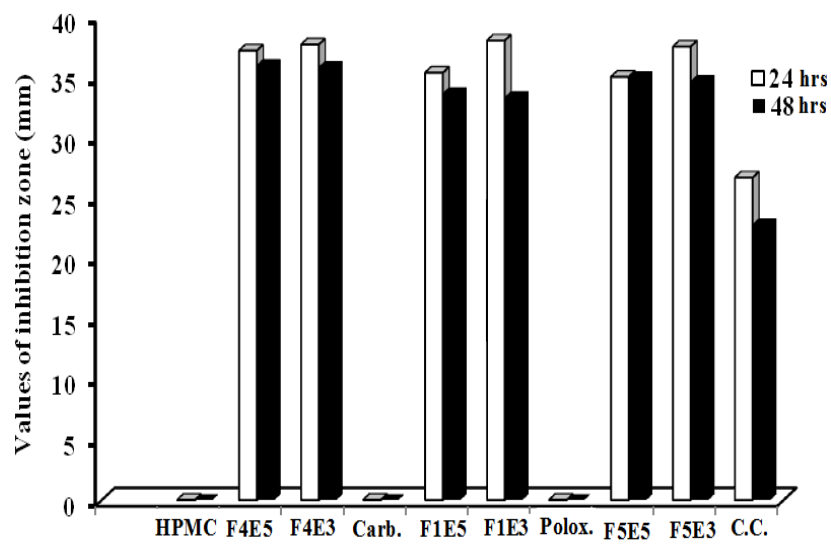

Fig. 11- Photograph showing the inhibition zones of different formulations of nystatin after $48 \mathrm{hr}$, C.C: commercial cream, P.G: plain gel, F5E3: gel containing 10\% propylene glycol, F5E5: gel containing $3 \%$ dimethyl formamide.

\section{Conclusion}

Nystatin was successfully incorporated into different gel formulations. Out of all penetration enhancers used, propylene glycol showed the highest effect on the amount drug permeated followed by dimethylformamide. The storage of nystatin gel bases for three months at three different temperatures causes insignificant change in $\mathrm{pH}$ values and that the degradation of nystatin was found to be zero-order reaction for all tested gel bases. The antifungal activity of all nystatin gels was found to be greater than that of commercial nystatin cream.

\section{References}

[1] Abdul Rasool B.K., Abu-Gharbieh E.F., Awni R.A., Alaa A. and Abdul Rasool A.A. (2010) J. Pharm. Sci., 3(1).

[2] Agoramoorthy G., Chandrasekaran M., Venkatesalu V. and Hsu M.J. (2007) J. Microbiol., 38, 739-742.

[3] Ceschel G.C., Maffei P. and Gentile M. (1999) Ind. Pharm., 25 (9) $1035-9$
[4] El-Houssieny B.M. and Hamouda H.M. (2010) Drug Discov. \& Therap., 4(1), 33-43.

[5] Fang J.Y., Hwavg T.L. and Leu Y.L. (2003) Int. J. Pharm., 250, 313-325.

[6] Gao S. and Singh J. (1998) Int. J. Pharm., 165, 45-55.

[7] Gwak H.S. and Chun I.K. (2002) Int. J. Pharm., 236, 57-64.

[8] Ibrahim M.M., Sammour O.A., Hammad M.A. and Megrab N.A. (2008) Sci. Tech., 9, 782-790.

[9] Larrucea E., Arellano A., Santony S. and Ygartua P. (2001) Drug Dev. Ind. Pharm., 27(3), 251-260.

[10]Marzouk M.A. PhD Thesis, Faculty of Pharmacy, Cairo University (1999)

[11]Marzouk M.A., Ammar A.A., Darwish M.K. and El-sayed H.A. (2011) J. Biomed. Sci., (3), 145-159.

[12]Miller S.C. and Drabik B.R. (1984) Int. J. Pharm., 18, 269-276.

[13]Reddy M.S. and Veerereddy P.R. (2011) Int. J. Pharm. Pharm. Sci., 3 (4), 148-152.

[14]Shembale A.I., Borole D.K. and Lohiya R.T. (2010) Int. J. Pharm., 2(5), 1-6.

[15]Shishu N. A. (2006) Int. J. Pharm., 326, 20-24.

[16]Singh S., Gajra B., Rawat M. and Muthu M.S. (2009) J. Pharm. Sci., 22(2), 193-8.

[17]Soll D.R., Galask R., Isley S., et al (1989) J. Clin. Microbiol., 27, 681-690.

[18]Supreetha S., Sharadadevi M., Sequeira P. S., et al (2011) J. Dent. Sci. Res., 2(2), 1-5.

[19]Wu P.C., Huang Y.B., Lin H.H. and Tsai Y.H. (1996) Int. J. Pharm., 145, 215-20.

[20]Yamane A.M., Williams A.C. and Barry B.W. (1995) J. Pharm. Pharmacol., 47, 978. 
Marzouk M.A., Ammar A.A., Darwish M.K. and El-Sayed H.A.

Table 1 - Composition of gel formulations containing penetration enhancers

\begin{tabular}{|c|c|c|c|c|c|c|c|c|c|c|c|c|c|c|c|}
\hline $\begin{array}{l}\text { Formulation } \\
\text { Code }\end{array}$ & Nystatin & $\begin{array}{c}\text { Carbopol } \\
934\end{array}$ & $\mathrm{NaCMC}$ & MC & HPMC & $\begin{array}{c}\text { Poloxamer } \\
407\end{array}$ & Ethanol & $\begin{array}{l}\text { Triethanol } \\
\text { amine }\end{array}$ & $\begin{array}{c}\text { Tween } \\
80\end{array}$ & $\begin{array}{l}\text { PropylenePc } \\
\text { glycol }\end{array}$ & $\begin{array}{l}\text { olyethylene } \\
\text {-glycol }\end{array}$ & $\begin{array}{l}\text { Dimethylf } \\
\text { ormamide }\end{array}$ & $\begin{array}{l}\text { Oleic E } \\
\text { acid }\end{array}$ & $\begin{array}{c}\text { Eucalyptus, } \\
\text { oil }\end{array}$ & Water to \\
\hline F1 & & 1 & & & & & & 1 & & & & & & & \\
\hline F2 & & & 5 & & & & & & & & & & & & \\
\hline F3 & & & & 3 & & & & & & & & & & & \\
\hline F4 & & & & & 3 & & & & & & & & & & \\
\hline F5 & & & & & & 20 & & & & & & & & & \\
\hline F1E1 & & 1 & & & & & 5 & 1 & & & & & & & \\
\hline F1E2 & & 1 & & & & & & 1 & 5 & & & & & & \\
\hline F1E3 & & 1 & & & & & & 1 & & 10 & & & & & \\
\hline F1E4 & & 1 & & & & & & 1 & & & 5 & & & & \\
\hline F1E5 & & 1 & & & & & & 1 & & & & 3 & & & \\
\hline F1E6 & & 1 & & & & & & 1 & & & & & 5 & & \\
\hline F1E7 & & 1 & & & & & & 1 & & & & & & 5 & \\
\hline F2E1 & & & 5 & & & & 5 & & & & & & & & \\
\hline F2E2 & & & 5 & & & & & & 5 & & & & & & \\
\hline F2E3 & & & 5 & & & & & & & 10 & & & & & \\
\hline F2E4 & & & 5 & & & & & & & & 5 & & & & \\
\hline F2E5 & & & 5 & & & & & & & & & 3 & & & \\
\hline F2E6 & & & 5 & & & & & & & & & & 5 & & \\
\hline F2E7 & & & 5 & & & & & & & & & & & 5 & \\
\hline F3E1 & & & & 3 & & & 5 & & & & & & & & 100 \\
\hline F3E2 & 1.72 & & & 3 & & & & & 5 & & & & & & 100 \\
\hline F3E3 & & & & 3 & & & & & & 10 & & & & & \\
\hline F3E4 & & & & 3 & & & & & & & 5 & & & & \\
\hline F3E5 & & & & 3 & & & & & & & & 3 & & & \\
\hline F3E6 & & & & 3 & & & & & & & & & 5 & & \\
\hline F3E7 & & & & 3 & & & & & & & & & & 5 & \\
\hline F4E1 & & & & & 3 & & 5 & & & & & & & & \\
\hline F4E2 & & & & & 3 & & & & 5 & & & & & & \\
\hline F4E3 & & & & & 3 & & & & & 10 & & & & & \\
\hline F4E4 & & & & & 3 & & & & & & 5 & & & & \\
\hline F4E5 & & & & & 3 & & & & & & & 3 & & & \\
\hline F4E6 & & & & & 3 & & & & & & & & 5 & & \\
\hline F4E7 & & & & & 3 & & & & & & & & & 5 & \\
\hline F5E1 & & & & & & 20 & 5 & & & & & & & & \\
\hline F5E2 & & & & & & 20 & & & 5 & & & & & & \\
\hline F5E3 & & & & & & 20 & & & & 10 & & & & & \\
\hline F5E4 & & & & & & 20 & & & & & 5 & & & & \\
\hline F5E5 & & & & & & 20 & & & & & & 3 & & & \\
\hline F5E6 & & & & & & 20 & & & & & & & 5 & & \\
\hline F5E7 & & & & & & 20 & & & & & & & & 5 & \\
\hline
\end{tabular}

